\title{
Erratum
}

eCAM 2004; 1(1): 49-62

\section{An Alternative Approach to Atopic Dermatitis: Part I-Case-Series Presentation}

Hiromi Kobayashi ${ }^{1,{ }^{*}}$, Kuniaki Takahashi ${ }^{2}$, Nobuyuki Mizuno ${ }^{1}$, Haruo Kutsuna ${ }^{1}$ and Masamitsu Ishii ${ }^{1}$

${ }^{1}$ Department of Dermatology, Osaka City University Graduate School of Medicine, Osaka, Japan, and ${ }^{2}$ Takahashi Dermatology Clinic, Daito City, Osaka, Japan

The author would like to apologize for the error in the above paper. The top line of Table 11 was missing in the original article. The correct version of Table 11 appears here.
Table 11. Components of Toki-shakuyaku-san (Japanese; Dang-gui-shaoyao-san in Chinese) extract granules for ethical use. Actions: reduces chill accompanied by water retention

\begin{tabular}{|c|c|c|c|}
\hline Japanese & grams & Scientific name & Actions \\
\hline Shakuyaku & 4.0 & Paeoniae Radix & $\begin{array}{l}\text { relieves spasm, relieves pain, } \\
\text { anticonvulsive, relieves blood } \\
\text { stasis }\end{array}$ \\
\hline Sojutsu & 4.0 & $\begin{array}{l}\text { Atractylodis Lanceae } \\
\text { Rhizoma }\end{array}$ & harmonizes water metabolism \\
\hline Takusha & 4.0 & Alismatis Rhizoma & removes excess body fluid \\
\hline Toki & 3.0 & Angelicae Radix & promotes blood circulation \\
\hline Bukuryo & 4.0 & Hoelen & removes excess body fluid \\
\hline Senkyu & 3.0 & Cnidii Rhizoma & promotes blood circulation \\
\hline
\end{tabular}

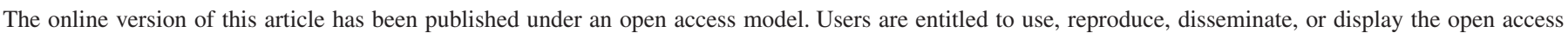

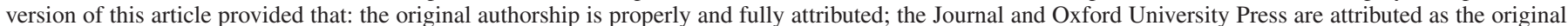

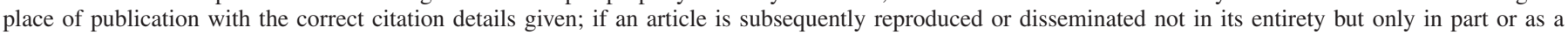
derivative work this must be clearly indicated. 


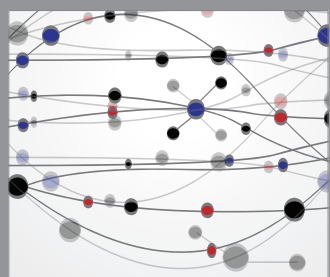

The Scientific World Journal
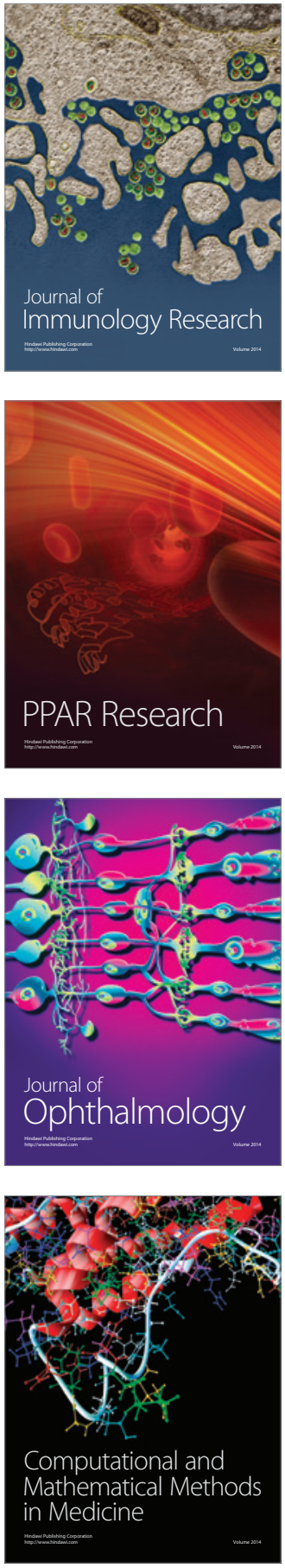

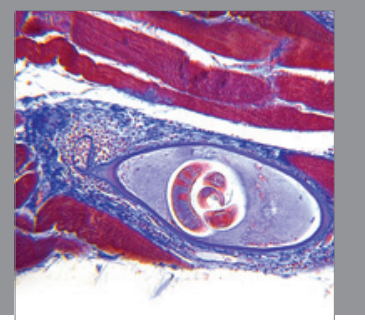

Gastroenterology

Research and Practice
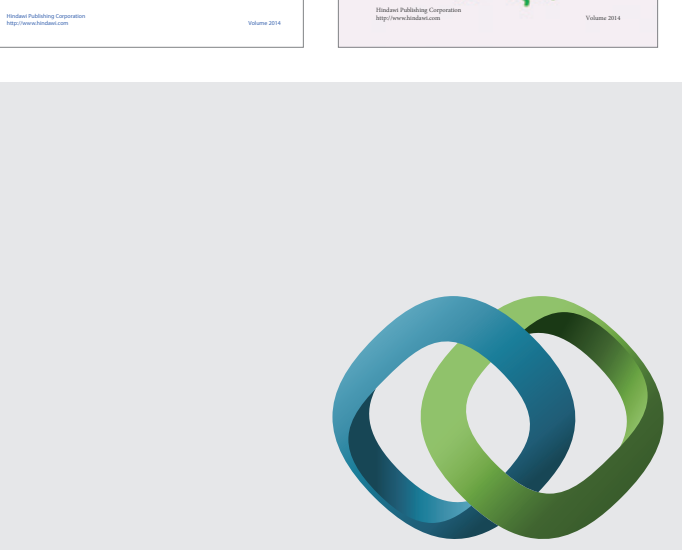

\section{Hindawi}

Submit your manuscripts at

http://www.hindawi.com
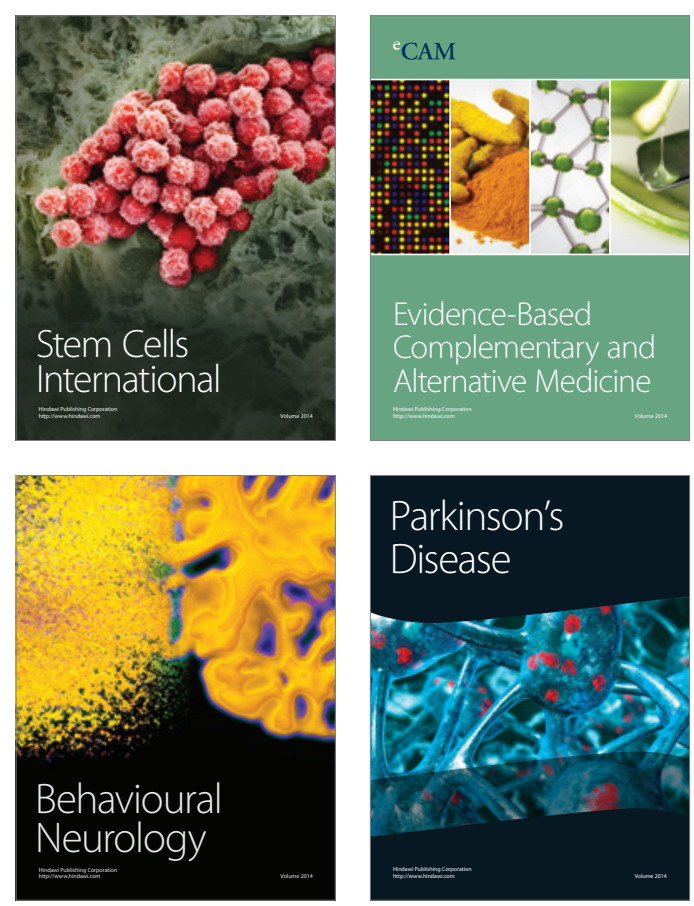

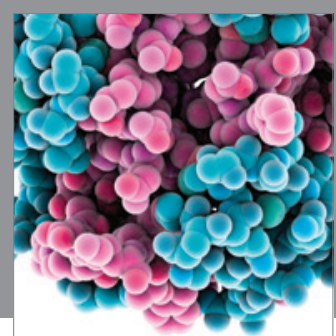

Journal of
Diabetes Research

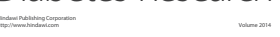

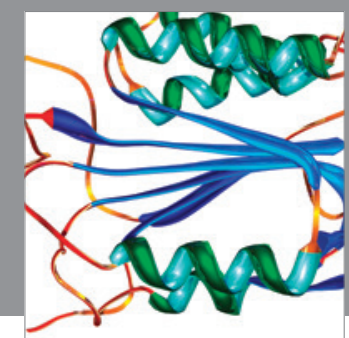

Disease Markers
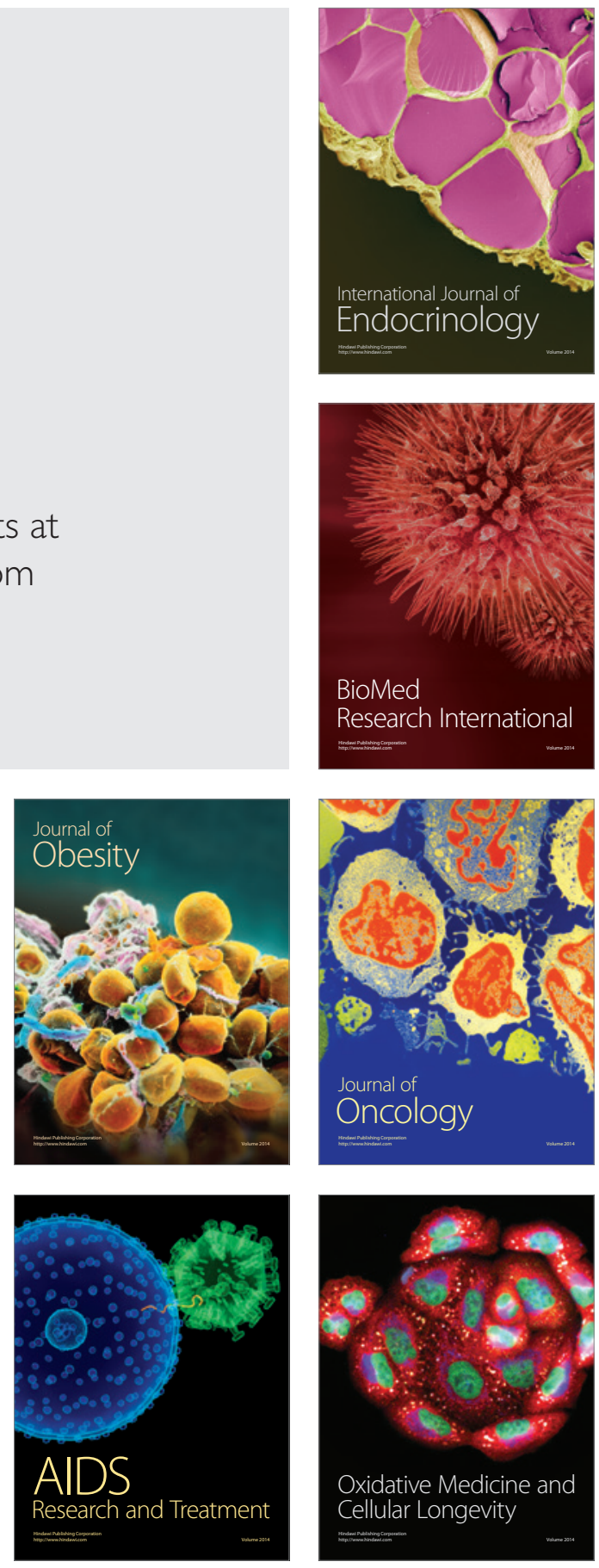